\title{
A Facile Synthesis and Biological Screening of Pyrimidine Derivatives under Ultrasonic Irradiations by $\mathrm{ZnCr}_{2} \mathrm{O}_{4}$ Nano-Particles Catalyst
}

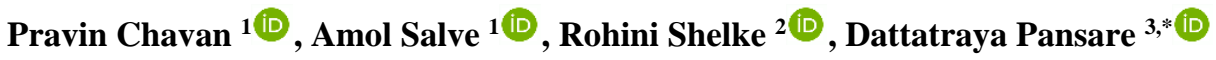 \\ 1 Department of Chemistry, Doshi Vakil College, Goregaon-Raigad,402103, MS, India \\ 2 Department of Chemistry, Sadguru Gadage Maharaj College Karad, 415124, MS, India \\ Department of Chemistry, Deogiri College, Aurangabad,431005, MS, India \\ Correspondence: dattatraya.pansare7@gmail.com (D.P.);
}

Received: 19.04.2021; Revised: 2.06.2021; Accepted: 5.06.2021; Published: 27.06.2021

\begin{abstract}
Using a recyclable catalyst, facile synthesis of pyrimidine derivatives (4a-e) is attributed through the one-pot multi-component reaction of 2-amino benzimidazole (1) substituted aromatic aldehydes (2a-e) with malononitrile (3) under ultrasonic irradiations. Synthesized derivatives might help society in getting more active pharmaceutical constituents. In this present work, series of substituted pyrimidine (4a-e) were synthesized and confirmed with different spectra characterization methods. The $\mathrm{ZnCr}_{2} \mathrm{O}_{4}$ nano-particles play a vital role in eco-friendly, highly efficient, recyclable heterogeneous nanocatalyst. Furthermore, synthesized pyrimidine derivatives showed significant biological activities. Advantages of this handy route are less reaction time, simple isolation, and highly yielded products.
\end{abstract}

Keywords: $\mathrm{ZnCr}_{2} \mathrm{O}_{4}$; one-pot multi-component reaction; aldehydes; pyrimidine; ultrasound irradiations.

(C) 2021 by the authors. This article is an open-access article distributed under the terms and conditions of the Creative Commons Attribution (CC BY) license (https://creativecommons.org/licenses/by/4.0/).

\section{Introduction}

Recently, multi-component reaction (MCRs) conveys their broader use in the field of organic synthesis due to the construction of new bonds within the time period. Significant benefits achieved through MCRs are high degree atom economy, minimize reaction time, ecofriendly, less product waste at the synthesis time [1-3].

A huge number of pyrimidine derivatives have been reported eliciting a wide range of biological activities such as antibacterial, antitumor, antiallergic, anti-inflammatory, analgesic, antimicrobial, an antifolate, tyrosine kinase, culostatic, calcium channel antagonists, antihypertensive, anti-leishmanial, tuber anti-convulsant, diuretic potassium-sparing, and antiaggressive activities [4-17].

The syntheses of pyrimidine derivatives have been carried out in the presence of $\mathrm{C}_{5} \mathrm{H}_{5} \mathrm{~N}, \mathrm{Me}_{2} \mathrm{NH}, \mathrm{Et}_{3} \mathrm{~N}, \mathrm{MgO}, \mathrm{NH}_{4} \mathrm{OAc}, p$-TSA, $\mathrm{N}_{2} \mathrm{H}_{4}$, and $\mathrm{InCl}_{3}$ etc. catalysts [18-28]. Still, lacuna observed in most of these synthetic approaches includes long reaction time, scarcity of recyclability for catalyst, longer reaction time, complicated isolation procedure, etc. Nowadays, safer, productive, simple, handled, hundred percent atom economy products, green approach catalyst is demanded. Hence, nanoparticle catalyst is one of the options due to recyclability. Nanoparticles of mixed metal oxides have been found applicable in physics, engineering, 
chemistry, pharmaceutical, and biological such as magnetic storage media, MRI contract agent, color imaging, ferrofluids, and high-frequency devices gas sensors and microwave devices [2933].

Here, In view of the above discussion and continuation of our previous work on thiazole and thiazolidinediones of medicinal interest [34-44], we have decided to report a simple and convenient facile synthesis of heterogeneous solid acid nanocatalyst successfully carried out organic syntheses and showed excellent results overcoming various drawbacks [45]. Considering these facts, a heterogenous nano-material was used as a catalyst during the synthesis of substituted pyrimidine. Substituted pyrimidines via MCRs route were synthesized from 2-amino benzimidazole (1), different aromatic aldehydes (2a-e) with malononitrile (3) under ultrasonic irradiations and were confirmed by characterization techniques such as IR, ${ }^{1} \mathrm{H}$ NMR, ${ }^{13} \mathrm{C}$ NMR, mass spectral analysis, and elemental analysis.

\section{Materials and Methods}

\subsection{General characterization experimental.}

Ultrasonic irradiation was carried out $(230 \mathrm{~V} \mathrm{AC}, 50 \mathrm{~Hz}$, liquid holding capacity of bath, $5.5 \mathrm{~L}$ ) at $70{ }^{\circ} \mathrm{C}$, for reaction. All chemicals were used AR grade, purchased from Sigma Aldrich. Synthesized pyrimidine derivatives were evaluated for spectroscopic characterization, such as IR spectra (KBr disc) were recorded on Bruker FT-IR spectrometer, ${ }^{1} \mathrm{H}$ NMR spectra were recorded on a Bruker DRX-300 and $400 \mathrm{MHz}$ NMR spectrometer, ${ }^{13} \mathrm{C}$ NMR spectra were recorded on a Bruker DRX75 and $100 \mathrm{MHz}$ NMR in CDCl $3 / \mathrm{DMSO}$-d6, and high-resolution mass spectra (HRMS) were recorded on Agilent 6520 (QTOF) ESI-HRMS instrument. Purity of synthesized pyrimidine derivatives was performed on TLC plate, using silica gel, 60F254 aluminum sheets as an adsorbent, and visualization was accomplished by iodine/ultraviolet light.

2.2. General procedure for synthesis of 4-amino-2-(R)-1,2-dihydroxybenzo[4,5]imidazo[1,2a]pyrimidine-3-carbonitrile derivatives (4a-e):

The solvent of acetonitrile having $\mathrm{ZnCr}_{2} \mathrm{O}_{4}(10 \mathrm{~mol} \%)$ was added successively to the reaction mixture 2-amino benzimidazole (1) $(1 \mathrm{mmol})$, aromatic aldehyde (2a-e) (1 mmol), and malononitrile (3) $(1.5 \mathrm{mmol})$ to round bottom flask. Then above reaction mass was ultrasonically irradiated (frequency of $50 \mathrm{~Hz}$ and power of $250 \mathrm{~V} \mathrm{AC}, 5.5 \mathrm{~L}, 70{ }^{\circ} \mathrm{C}$ ) for an appropriate time. The reaction pot was placed in a sonication bath, and the surface of the reactants in round bottom flasks was placed slightly lower than the water level in the sonication bath. The reaction progression and confirmation were done by TLC. After the completion of the reaction, the nanocatalyst was recovered through filtration, and usual isolation obtained the crude products. The newly synthesized pyrimidine analogs were eluted in ethyl acetate/nhexane. Synthesized products were recrystallized using pure ethanol.

2.2.1. 4-amino-2-(4-hydroxyphenyl)-1,2-dihydroxybenzo[4,5]imidazo[1,2-a]pyrimidine-3carbonitrile(4a).

Brownish crystals, M.P. $211-214{ }^{\circ} \mathrm{C}, \mathrm{ES}-\mathrm{MS} \mathrm{m} / \mathrm{z}(\%): 304.34$. FTIR $\left(\mathrm{KBr} \mathrm{cm}^{-1}\right): 3298$, 3135, 2177, 1688, 1633, 1601, 1155. ${ }^{1} \mathrm{H}$ NMR $\left.400 \mathrm{MHz}, \mathrm{DMSO}\right) \delta 9.19$ (s, 2H, $\mathrm{D}_{2} \mathrm{O}$ exchangeable $\left.\mathrm{NH}_{2}\right), 8.65$ (s, 1H, NH), 7.60 (m, 2H,Ar), 7.10-7.49 (m, 2H,Ar), 7.07 (s, 1H,CH), 
6.99-6.99 (m, 2H, Ar), 6.77-6.95, (m, 2H, Ar), 5.30 (s, 1H, OH), ${ }^{13} \mathrm{C}$ NMR (100 MHz, DMSO): $151.86,149.88,148.44,132.92$, 129.64, 127.28, 123.78, 120.34, 119.32, 118.75, 116.64, 112.76, 111.30, 61.05, 53.39. Elemental Analysis: C, 67.32; H, 4.32; N, 23.09; O, 5.27

2.2.2. 4-amino-2-(4-cyanophenyl)-1,2-dihydroxybenzo[4,5]imidazo[1,2-a]pyrimidine-3carbonitrile(4b).

Yellow crystals, M.P. $223-225^{\circ} \mathrm{C}$, ES-MS m/z (\%): 313.34. FTIR $\left(\mathrm{KBr} \mathrm{cm}^{-1}\right): 3396$, 2925, 1525, 2251, 1621, 1509. 1152. ${ }^{1} \mathrm{H}$ NMR $\left.400 \mathrm{MHz}, \mathrm{DMSO}\right) \delta 9.22\left(\mathrm{~s}, 2 \mathrm{H}, \mathrm{D}_{2} \mathrm{O}\right.$ exchangeable $\mathrm{NH}_{2}$ ), 8.10 (s, 1H,NH), 8.04-7.62 (d, 2H,Ar), 7.20-7.05 (m, 2H, Ar), 6.98-6.96, (m, 2H, Ar), 7.62-6.54 (m, 2H,Ar), 5.35 (s,1H, CH,). ${ }^{13} \mathrm{C}$ NMR (100 MHz, DMSO): 157.94, $152.13,149.37,144.34,143.97,129.80,123.63,123.65,120.15,119.37,116.99,116.57$, 115.38, 113.17, 112.25, 62.90, 53.97. Elemental Analysis: C, 69.22; H, 3.87; N, 26.91

2.2.3. 4-amino-2-(3-hydroxy-4-methoxyphenyl)-1,2-dihydroxybenzo[4,5]imidazo[1,2a]pyrimidine-3-carbonitrile (4c).

Yellow crystals, M.P. $230-233^{\circ} \mathrm{C}$, ES-MS m/z (\%): 334.35. FTIR $\left(\mathrm{KBr} \mathrm{cm}^{-1}\right)$ : 3244 , 2912, 2100, 1629, 1151. ${ }^{1} \mathrm{H}$ NMR $\left.400 \mathrm{MHz}, \mathrm{DMSO}\right) \delta 9.13$ (s, 2H, $\mathrm{D}_{2} \mathrm{O}$ exchangeable $\mathrm{NH}_{2}$ ), 8.10 (s, 1H,NH), 8.04-7.60 (d, 2H,Ar), 7.20-7.18 (m, 2H, Ar), 6.98-6.94, (m, 2H, Ar), 6.66 (s, 1H,Ar), 6.54 (s, 1H, CH), 5.35 (s, OH,), 3.68 (s, 3H). ${ }^{13} \mathrm{C}$ NMR (100 MHz, DMSO): 157.94, $152.13,149.37,144.23,143.97,129.80,129.63,120.15,119.37,116.99,116.57,115.38$, 113.17, 112.25, 62.90, 56.97, 49.42. Elemental Analysis: C, 64.86; H, 4.54; N, 21.01; O, 9.60

2.2.4. 4-amino-2-(4-methoxyphenyl)-1,2-dihydroxybenzo[4,5]imidazo[1,2-a]pyrimidine-3carbonitrile (4d).

White crystals, M.P. $200-203{ }^{\circ} \mathrm{C}$, ES-MS m/z (\%): 318.35. FTIR $\left(\mathrm{KBr} \mathrm{cm}^{-1}\right): 3434$, 32480, 3210, 2921, 1523, 2250, 1155. ${ }^{1} \mathrm{H}$ NMR $\left.400 \mathrm{MHz}, \mathrm{DMSO}\right) \delta 9.24$ (s, 2H, $\mathrm{D}_{2} \mathrm{O}$ exchangeable $\left.\mathrm{NH}_{2}\right), 8.11(\mathrm{~s}, 1 \mathrm{H}, \mathrm{NH}), 7.88(\mathrm{~m}, 2 \mathrm{H}, \mathrm{Ar}), 7.57-7.59$ (m, 2H,Ar), 7.07-7.18 (m, $2 \mathrm{H}, \mathrm{Ar}), 6.98-6.31,(\mathrm{~m}, 2 \mathrm{H}, \mathrm{Ar}), 5.07(\mathrm{~s}, 1 \mathrm{H}, \mathrm{CH}), 3.8\left(\mathrm{~s}, 3 \mathrm{H}, \mathrm{OCH}_{3}\right),{ }^{13} \mathrm{C} \mathrm{NMR}(100 \mathrm{MHz}$, DMSO): 157.92, 152.03, 148.97, 143.94, 143.37, 129.00, 123.26, 123.55, 120.05, 118.37, 118.57, 115.61, 114.00, 111.95, 62.98, 53.95. Elemental Analysis: C, 68.13; H, 4.76; N, 22.07; O, 5.04 .

2.2.5. 4-amino-2-(4-chlorophenyl)-1,2-dihydroxybenzo[4,5]imidazo[1,2-a]pyrimidine-3carbonitrile(4e).

White crystals, M. P. $210-212^{\circ} \mathrm{C}$, ES-MS m/z (\%): 322.77. FTIR $\left(\mathrm{KBr} \mathrm{cm}^{-1}\right): 3425$, 3320, 2951, 2971, 2881, 1533, 2233, 1640, 1596, 1125. ' $\mathrm{H}$ NMR $400 \mathrm{MHz}, \mathrm{DMSO}) \delta 9.22$ (s, 2H, $\mathrm{D}_{2} \mathrm{O}$ exchangeable $\left.\mathrm{NH}_{2}\right), 8.38(\mathrm{~s}, 1 \mathrm{H}, \mathrm{NH}), 7.84(\mathrm{~m}, 2 \mathrm{H}, \mathrm{Ar}), 7.32(\mathrm{~m}, 2 \mathrm{H}, \mathrm{Ar}), 7.03-7.15$ (m, 2H, Ar), 6.38-6.68, (m, 2H, Ar), 5.06 (s, 1H, CH,). ${ }^{13} \mathrm{C}$ NMR (100 MHz, DMSO): 153.39, $152.67,150.86,149.97,144.00,131.47,129.74,123.03,120.12,119.31,116.44,113.94$, 112.60, 112.49, 112.23, 61.56, 56.10. Elemental Analysis: C, 63.46; H, 3.76; Cl, 11.02; N, 21.77 . 


\subsection{Biological Evaluation.}

\subsubsection{Anti-tuberculosis activity}

In vitro anti-tuberculosis activity was carried out using the CLAIRO COMBI method on [46] Liquefied sterile Lowenstein-Jensen ager. M. Tuberculosis bacteria and Streptomycin as a positive control.

2.3.2. Anti-inflammatory activity.

In vitro anti-inflammatory activity was carried out by the red blood cell (HRBC) membrane stabilization method. ${ }^{47-48}$ In this test, fresh whole human blood $(5 \mathrm{ml})$ was collected and transferred to the centrifuge tubes containing sodium citrate, centrifuged at $3000 \mathrm{rpm}$ for ten minutes. These tubes were then washed 3 times with an equal volume of normal saline. The reaction mixture constituting of $1.0 \mathrm{ml}$ of the test sample, $0.5 \mathrm{ml}$ of $(10 \%) \mathrm{HRBC}$ suspension, $1 \mathrm{ml}$ of phosphate buffer, $1 \mathrm{ml}$ of hypo saline was incubated at $37^{\circ} \mathrm{C}$ for 30 minutes and then centrifuged at $3000 \mathrm{rpm}$ (30 minutes). The hemoglobin content of the supernatant solution was estimated spectrophotometrically at $560 \mathrm{~nm}$. Diclofenac was used as a standard and control.

\section{Results and Discussion}

In this work, synthesis of substituted pyrimidines via MCRs from 2-amino benzimidazole (1), substituted aromatic aldehydes (2a-e), and malononitriles (3) were selected as a model reaction to screening reactions the reaction parameters by using nanocatalyst $\left(\mathrm{ZnCr}_{2} \mathrm{O}_{4}\right)$ under ultrasonic irradiation condition.

\section{1. $\mathrm{ZnCr}_{2} \mathrm{O}_{4}$ nanocatalyst recycles.}

In the present work, recycle process of $\mathrm{ZnCr}_{2} \mathrm{O}_{4}$ for the model reaction was studied. Isolation of nanoparticles was done by centrifuging reaction mass after diluting ethyl acetate solvent. We have mentioned here the recoverable percentage of nanocatalyst by five cycles in Figure 1.

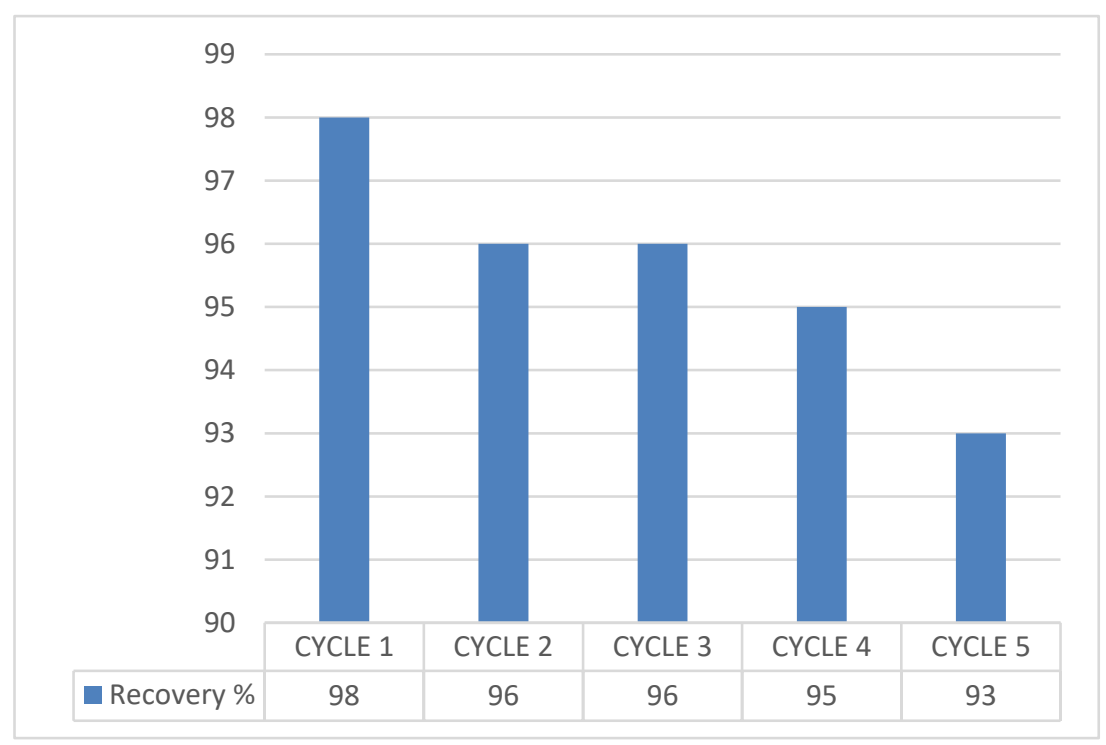

Figure 1. $\mathrm{ZnCr}_{2} \mathrm{O}_{4}$ recycle system. 


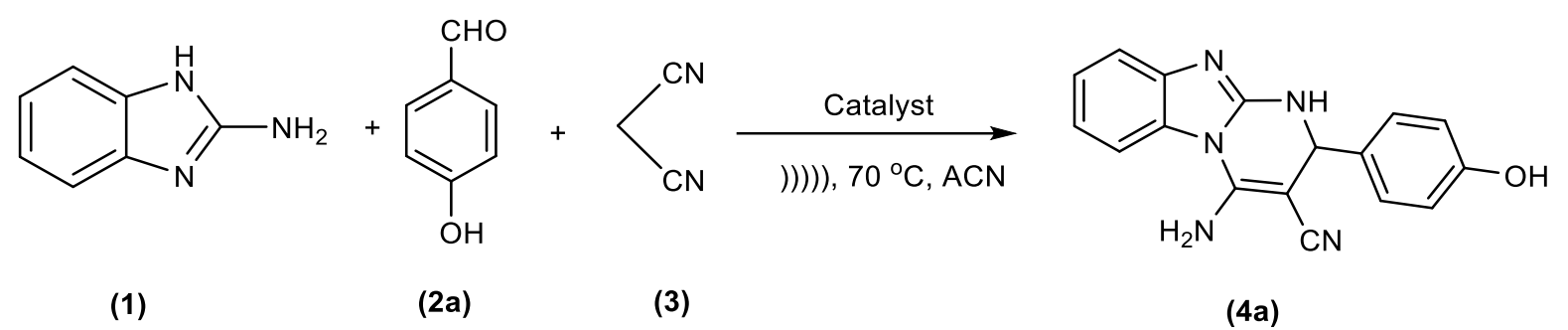

Scheme 1. Model reaction for screening of synthesis of substituted pyrimidine.

\subsection{Synthesis of pyrimidine.}

The eco-friendly and efficient nature of synthesized $\mathrm{ZnCr}_{2} \mathrm{O}_{4}$ nanoparticles, as nanocatalyst, is purposefully used to synthesize substituted pyrimidines (4a-e) through MCRs. Firstly, the selected reaction model from 2-amino benzimidazole and malononitrile with 4methoxy benzaldehyde was allowed to be screened in MCRs condition under ultrasonic irradiations at $70^{\circ} \mathrm{C}$ in neat condition (Scheme 1). The amount of nanocatalyst was determined to go for substrate scope; the model reaction was carried out with or without nanocatalyst. An inadequate amount of product was observed in the absence of catalyst (Table 1). Thus, we focused on the insertion of $\mathrm{ZnCr}_{2} \mathrm{O}_{4}$ nanoparticles so as to carry out the present reaction under neat conditions. This resulted in product yield is better. $10 \mathrm{~mol} \%$ of nanocatalyst was optimum, as it provided excellent results concerning the formation of the desired product properly. With the optimized condition of model reaction on hand, various substituted aromatic aldehydes, 2amino benzimidazole, and malononitrile were studied under the same reaction conditions. Pyrimidine derivatives were carried out by 2-amino benzimidazole (1), substituted aromatic aldehydes (2a-e), and malononitrile (3) in acetonitrile solvent using heterogenous $\mathrm{ZnCr}_{2} \mathrm{O}_{4}$ nanocatalyst under ultrasonic irradiations.

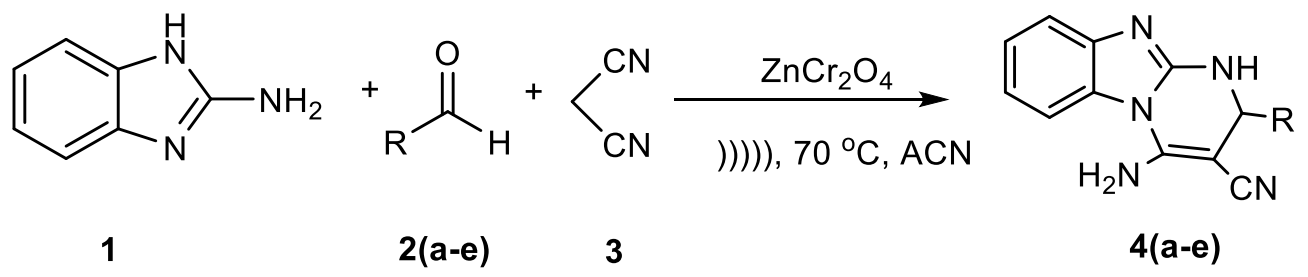

Scheme 2. Synthesis of substituted pyrimidine derivatives (4a-e) using heterogenous $\mathrm{ZnCr}_{2} \mathrm{O}_{4}$ under ultrasonic irradiation in acetonitrile solvents.

Table 1. Optimization of reaction time and amount (mol \%) $\mathrm{ZnCr}_{2} \mathrm{O}_{4}$ catalyst in acetonitrile for the model reaction

\begin{tabular}{l|l|l|l} 
Entry & $($ Mole $\%)$ catalyst & Time (Min.) & Yield (\%) \\
\hline 1 & None & 150 & 20 \\
\hline 2 & 10 & 150 & 77 \\
\hline 3 & 10 & 120 & 77 \\
\hline 4 & 10 & 80 & 80 \\
\hline 5 & 10 & 50 & 85 \\
\hline 6 & 10 & 40 & 71 \\
\hline 7 & 5 & 50 & 62 \\
\hline 8 & 15 & 50 & 81 \\
\hline 9 & 20 & 50 & 83
\end{tabular}

Reaction conditions: 2 -amino benzimidazole (1) (1 mmol), 4-methoxy benzaldehyde (2c) (1 mmol), malononitrile (3) (1.5 mmol), acetonitrile solvent under ultrasonic irradiation $\left(70^{\circ} \mathrm{C}\right)$. 
Table 2. $\mathrm{ZnCr}_{2} \mathrm{O}_{4}$ nano-catalysed multi-component synthesis of 4-amino-2-( $\left.\mathrm{R}\right)-1,2-$ dihydroxybenzo[4,5]imidazo[1,2-a]pyrimidine-3-carbonitrile Derivatives (4a-e)

\begin{tabular}{l|l|l|l|l} 
Entry & $\mathbf{R}_{\mathbf{1}}$ & Product & Time (min.) & Isolated yield (\%) \\
\hline 1 & $4-\mathrm{HO}-\mathrm{C}_{6} \mathrm{H}_{4}$ & $4 \mathrm{a}$ & 47 & 83 \\
\hline 2 & $4-\mathrm{CN}-\mathrm{C}_{6} \mathrm{H}_{4}$ & $4 \mathrm{~b}$ & 35 & 90 \\
\hline 3 & $3-\mathrm{MeO}-4-\mathrm{HO}_{-}-\mathrm{C}_{6} \mathrm{H}_{3}$ & $4 \mathrm{c}$ & 44 & 80 \\
\hline 4 & $4-\mathrm{MeO}-\mathrm{C}_{6} \mathrm{H}_{4}$ & $4 \mathrm{~d}$ & 43 & 85 \\
\hline 5 & $4-\mathrm{Cl}-\mathrm{C}_{6} \mathrm{H}_{4}$ & $4 \mathrm{e}$ & 39 & 87
\end{tabular}

Reaction conditions: 2-amino benzimidazole (1) (1 mmol), substituted aromatic aldehyde (2a-e) (1 mmol), malononitrile (3) $(1.5 \mathrm{mmol})$, acetonitrile solvent under ultrasonic irradiation $\left(70^{\circ} \mathrm{C}\right)$.

The reaction progress was checked by thin-layer chromatography (TLC), which indicated the formation of substituted pyrimidines (4a-e) through MCRs (Scheme 2). After completing the reaction, the reaction mass was cooled at room temperature, and then an appropriate amount of ethyl acetate was added. Residues of $\mathrm{ZnCr}_{2} \mathrm{O}_{4}$ were recovered through G1 sintered funnel filtration and finally, using double distilled water, dried, and this catalyst was used for the next reaction. The benefits of present synthesis were high efficiency, enhancement in yield, high rate of reaction, and simple isolation process.

Parallel, the effect of ultrasonic irradiation, electron-withdrawing, electron releasing, and halogen groups in different, on aromatic aldehyde ring in the synthesis of 4-amino-2-(R)1,2-dihydroxybenzo[4,5]imidazo[1,2-a]pyrimidine-3-carbonitrile Derivatives (4a-e) were studied and illustrated in Table 2. Aldehyde-containing electron-withdrawing groups decreased reaction time, slightly increased the percentage of yields. In contrast, electron releasing groups increased the reaction time. No outstanding effect on the percentage of yields was observed due to the effect of ultrasonic irradiations (Table 2).

\subsection{Biological evaluations.}

In-vitro synthesized compounds (4a-e) showed anti-tuberculosis and anti-inflammatory activity (Tables $3 \& 4)$.

\subsubsection{Anti-tuberculosis analysis.}

Table 3. Anti-tuberculosis evaluation for synthesized pyrimidine derivatives.

\begin{tabular}{l|l|l} 
Entry & Product & Anti-tuberculosis (zone in mm) \\
\hline 1 & $4 \mathrm{a}$ & 10 \\
\hline 2 & $4 \mathrm{~b}$ & 13 \\
\hline 3 & $4 \mathrm{c}$ & 14 \\
\hline 4 & $4 \mathrm{~d}$ & 11 \\
\hline 5 & $4 \mathrm{e}$ & 15 \\
\hline 6 & Streptomycin & 18
\end{tabular}

The compound $\mathbf{4 e}$ showed activity in the higher while $\mathbf{4 a} \& \mathbf{4 d}$ lower zones (Table $\mathbf{3}$ ).

3.3.2. Anti-inflammatory analysis.

Table 4. Anti-inflammatory evaluation for synthesized pyrimidine derivatives.

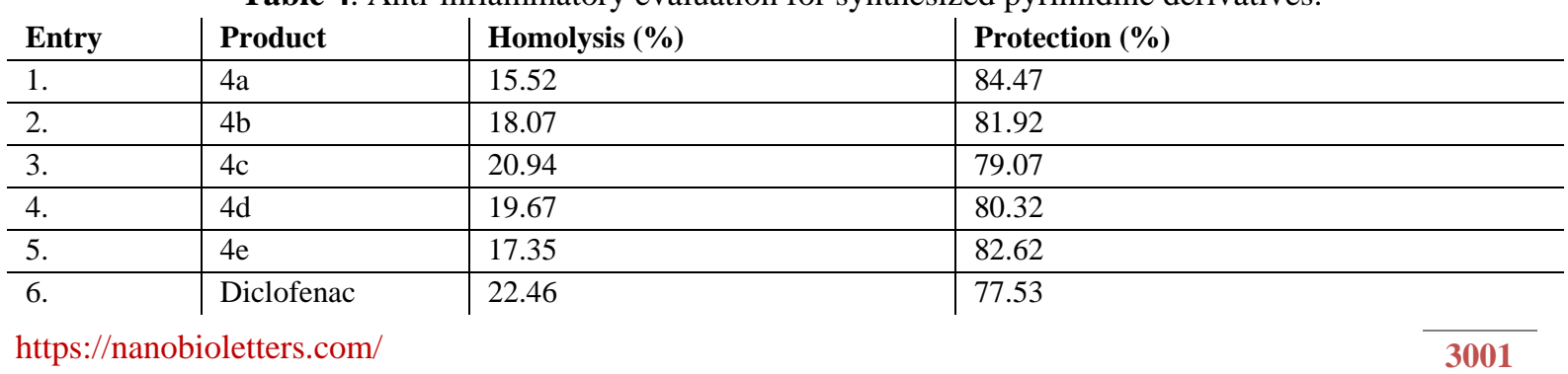


Compound $4 \mathrm{c}$ showed the highest percentage of HRBC membrane stabilization, and compound 4a showed the lowest percentage of HRBC membrane stabilization (Table 4).

\section{Conclusions}

We conclude that our discovered method is newer for the synthesis of 4-amino-2-(R)1,2-dihydroxybenzo[4,5]imidazo[1,2-a]pyrimidine-3-carbonitrile derivatives (4a-e) from 2amino benzimidazole (1) (1 mmol), substituted aromatic aldehyde (2a-e) (1 mmol), malononitrile (3) $(1.5 \mathrm{mmol})$, using a green catalyst $\left(\mathrm{ZnCr}_{2} \mathrm{O}_{4}\right)$ in acetonitrile solvent under ultrasonic irradiation. The discovered method provides various advantages such as excellent yield, saved reaction time, easy handling, high reaction rate, one-time addition of the reactant, and a high percentage of yields. Also the synthesized compounds 4-amino-2-(R)-1,2dihydroxybenzo[4,5]imidazo[1,2-a]pyrimidine-3-carbonitrile derivatives (4a-e) elicited antituberculosis activity against $M$. tuberculosis. Hence, we suggest the use of synthesized pyrimidine derivatives (4a-e) against (T.B.). The series of pyrimidine derivatives (4a-e) showed potent in vitro anti-inflammatory activity.

\section{Funding}

This research received no external funding.

\section{Acknowledgments}

The authors are grateful to the principal, Doshi Vakil College, Goregaon Raiagad, for providing research-related necessary facilities.

\section{Conflicts of Interest}

The authors declare that there is no conflict of interest regarding the publication of this article.

\section{References}

1. Emel, P.; Zuhal, T. Three-component aza-Diels-Alder reactions using $\mathrm{Yb}(\mathrm{OTf})_{3}$ catalyst under conventional/ultrasonic techniques. Ultrasonic sonochem. 2014, 21, 1600-1607, https://doi.org/10.1016/j.ultsonch.2014.01.009.

2. Sunderhaus, J. D.; Dockendorff, C.; Martin, S. F. Applications of Multi-component Reactions for the Synthesis of Diverse Heterocyclic Scaffolds. Org. Lett. 2007, 9, 4223-4226, https://doi.org/10.1002/chem.200802140.

3. Domling, A.; Wang, W.; Wang, K, Chemistry and biology of multi-component Reactions. Chem. Rev. 2012, 112(6), 3083-3135, https://doi.org/10.1021/cr100233r.

4. Bhat, A. R.; Dongre, R. S.; Selokar, R. S. Potent in vitro antibacterial and antifungal activities of pyrano[2,3d]pyrimidine derivatives with quantitative yield. Int. J. Pharma and Bio. Sci. 2014, 5, 422-430.

5. Grivsky, E. M.; Lee, S. C.; Sigel, W.; Duch, D. S.; Nichol, C. A; Synthesis and antitumor activity of 2,4diamino-6-(2,5-dimethoxybenzyl)-5-methylpyrido[2,3-d]pyrimidine. J. Med. Chem. 1980, 23, 327-329, https://doi.org/10.1021/jm00177a025.

6. Kitamura, N.; Ohnishi, A. Pyrimidopyrimidinedione derivatives and their use antiallergic agent. Eur. Pat. 163599; Chem. Abstr., 1984; 104, 186439.

7. Trofimov, F. A.; Tsyshkova, N. G.; Zotova, S. A.; Grinev, A. N. Synthesis of a new antiviral agent, arbidole Pharma. Chem. Jou. 1993, 27, 75-76, https://doi.org/10.1007/BF00772858.

8. Donkor, I. O.; Klein, C. L.; Liang, L.; Zhu, N.; Bradley, E.; Clark, A. M. Synthesis and Antimicrobial Activity of Some 6,7-Annulated Pyri-do[2,3-d]pyrimidines. J. Pharmaceutical Sci. 1995, 84, 661-665, https://doi.org/10.1002/jps.2600840526. 
9. Rosowsky, A.; Mota, C. E.; Queener, S. F. Synthesis and antifolate activity of 2,4-diamino-5,6,7,8tetrahydropyrido[4,3-d]pyrimidine analogues of trimetrexate and piritrexim. J. Heterocyclic Chem. 1995, 32, 335-340, https://doi.org/10.1002/jhet.5570320155.

10. Thompson, A. M.; Bridges, A. J.; Fry, D. W.; Kraker, A. J.; Denny, W. A. Tyrosine kinase inhibitors. 7amino-4-(phenylamino)- and 7-amino-4-[(phenylmethyl)amino]pyrido[4,3-d]pyrimidines: a new class of inhibitors of the tyrosine kinase activity of the epidermal growth factor receptor. J. Med. Chem. 1995, 38, 3780-3788, https://doi.org/10.1021/jm00019a007.

11. Bystryakova, I. D.; Burova, O. A.; Chelysheva, G. M.; Zhilinkova, S. V.; Smirnova, N. M.; Safonova T. S. Synthesis and Biological Activity of Pyridol[2,3-d]py- rimi-dines. J. Pharmaceutical Chem. 1991, 25, 874876, https://doi.org/10.1007/BF00778976.

12. Pastor, A.; Alajarin, R.; Vaquero, J. J.; Alvarez-Builla, J.; Casa-Juana, M. F.; Sunkel, C.; Priego, J. G.; Fonseca, I.; Aparicio, J. S.; Synthesis and Structure of New Pyrido[2,3-d]pyrimidine Derivatives with Calcium Channel Antagonist Activity. Tetrahedron 1994, 50, 8085-8098, https://doi.org/10.1016/s00404020(01)85291-1.

13. Ellingboe, J. W.; Princeton, N. J.; Substituted Pyridopyrimidines and Antihypertensives. Chem. Abstr., 124, Article ID: 176134. Patent Number: 5,466,692, https://pubchem.ncbi.nlm.nih.gov/patent/US5466692.

14. Agarwal, A.; Ashutosh, R.; Goyal, N.; Chauhan, P. M. S.; Gupta, S. Dihydropyrido[2,3-d]pyrimidines as a new class of antileishmanial agents. Bio-organic \& Med. Chem. 2005, 13, 6678-6684, https://doi.org/10.1016/j.bmc.2005.07.043.

15. Deyanov, A. B.; Niyazov, R. K.; Nazmetdivov, F. Y.; Syropyatov, B. Y.; Kolla, V. E.; Konshin, M. E.; Synthesis and Biological Activity of Amides and Nitriles of 2- Arylamino-5-carboxy(carbethoxy)-6methylnicotinic ac-ids and 1-aryl-6-carbethoxy-7-methyl-4-oxo-1,4-dihydro- pyrido[2,3-d]pyrimidine. $J$. Pharmaceutical Chem. 1991, 25, 248-250, https://doi.org/10.1007/BF00772106.

16. Larizza Hellen, S. M.; Flavia, T. M.; Luiz, A. S.; Mauricio, H. M. Biological activity of dihydropyrimidinone (DHPM) derivatives: A systematic review. Eur. J. Med. Chem. 2018, 143, 1779-1789, https://doi.org/10.1016/j.ejmech.2017.10.073.

17. Dhanabal, K.; Biswajit, G. R.; Joana, R. P.; Johan, N.; Satheeshkumar, N.; Subhasis, M.; Musfiqua, M.; Lieve, N. Synthesis and in vitro antiviral evaluation of 4-substituted 3,4-dihydropyrimidinones. Bioorg. Med. Chem Lett. 2017, 27, 139-142, https://doi.org/10.1016/j.bmcl.2016.12.010.

18. Sheibani, H.; Hassani, F. Chemoselective synthesis of 4-oxo-2-aryl-4,10-dihydropyrimido [1,2a][1,3] benzimidazol-3-yl cyanides via [3+3] atom combination of 2-aminobenzimidazole with ethyl- $\alpha$ cyanocinnamoates. J. Het. Chem. 2011, 48, 915-920, https://doi.org/10.1002/jhet.640.

19. Sheibani, H.; Seifi, M.; Bazgir, A. Three-component synthesis of pyrimidine and pyrimidinone derivatives in the presence of high-surface-area $\mathrm{MgO}$, a highly effective heterogeneous base catalyst. Syn. Comm. 2009, 39, 1055-1064, https://doi.org/10.1080/00397910802474982.

20. Wendt, M. D.; Kunzer, A.; Henry, R. F.; Cross, J.; Pagano, T. G. Regiochemistry of addition of aminoheterocycles to $\alpha$-cyanocinnamonitriles: formation of aza-bridged bi- and tricycles. Tetrahedron Lett. 2007, 48, 6360-6363, https://doi.org/10.1016/j.tetlet.2007.07.039.

21. Jairo, Q.; Henry, I.; Braulio, I.; Rodrigo, A.; Justo, C.; Adolfo, S.; Manuel, N. New aspects on the selective synthesis of 7-arylpyrido[2,3-d]pyrimidines. Tetrahedron. 2002, 58, 4873-4877, https://doi.org/10.1016/S0040-4020(02)00433-7.

22. Bassyouni, F. A.; Ismail, I. I. Polynuclear heterocyclic compounds from 2-aminobenzimidazole. Afinidad, 2011 , 58 , 375-379, https://www.researchgate.net/publication/289473027_Polynuclear_heterocyclic_compounds_from_2aminobenzimidazole.

23. Komykhov, S. K.; Ostras, A. R.; Kostanyan, S. M.; Desenko, D. V.; Orlov, H.; Meier, J.; The reaction of amino-imidazoles,-pyrazoles and-triazoles with $\alpha, \beta$-unsaturated nitriles. Heterocycl. Chem. 2005, 42, 11111116, https://doi.org/10.1002/jhet.5570420612.

24. El-Desoky, E. I.; Aboul-Fetouh, S.; Metwally, M. A. Bis(methylthio)methylene malononitrile in the synthesis of heterocyclic compounds with bridgehead nitrogen. J. Chem. Technol. Biotechnol. 1996, 67, 153-156, https://doi.org/10.1002/(SICI)1097-4660(199610)67:2<153::AID-JCTB554>3.0.CO;2-H.

25. Keshari, K.; Singh, A. K.; Raj, V.; Rai, A.; Trivedi, P.; Ghosh, B.; Kumar, U.; Rawat, A.; Kumar, D.; Saha S. $p$-TSA-promoted syntheses of 5H-benzo [h] thiazolo [2, 3-b] quinazoline and indeno [1, 2-d] thiazolo [3, 2-a] pyrimidine analogs: molecular modeling and in vitro antitumor. Drug design, development and therapy 2017, 11, 1623-1642, https://doi.org/10.2147/DDDT.S136692. 
26. Heravi, M. M.; Daraie, M. A Novel and Efficient Five-Component Synthesis of Pyrazole Based Pyrido[2,3d]pyrimidine-diones in Water: A Triply Green Synthesis. Molecules. 2016, 21(4), 441, https://doi.org/10.3390/molecules21040441

27. Corma, R. M.; Martin-Aranda, Application of solid base catalysts in the preparation of prepolymers by condensation of ketones and malononitrile. Appl. Catal., A. 1993, 105, 271-279, https://doi.org/10.1016/0926-860X(93)80252-L.

28. Reddy, M.; Khan, A. Recent Advances on $\mathrm{TiO}_{2}-\mathrm{ZrO}_{2}$ Mixed Oxides as Catalysts and Catalyst Supports. Catal. Rev. Sci. Eng. 2005, 47, 257-296, https://doi.org/10.1081/CR-200057488.

29. Service, R. F. Nanocrystals May Give Boost to Data Storage. Science 2000, 287, 1902-1903, https://doi.org/10.1126/science.287.5460.1902.

30. Chen, H.; Liao, M. H. Preparation and characterization of YADH-bound magnetic nanoparticles. J. Mol. Catal. B: Enzyme 2002, 16, 283-291, https://doi.org/10.1016/S1381-1177(01)00074-1.

31. Kishimoto, M.; Sakurai, Y.; Ajima, T. Magneto-optical properties of Ba-ferrite particulate media. J. Appl. Phys. 1994, 76, 7506-7509, https://doi.org/10.1063/1.357981.

32. Sousa, M. H.; Hasmonay, E.; Depeyrot, J.; Tourinho, F. A.; Bacri, J. C.; Dubois, E.; Perzynski, R.; Raikher, L. $\mathrm{NiFe}_{2} \mathrm{O}_{4}$ nanoparticles in ferrofluids: evidence of spin disorder in the surface layer. J. Mag. Magnetic Materials. 2002, 242-245, 572-574, https://doi.org/10.1016/S0304-8853(01)01122-2.

33. Bangale S. V.; Patil D. R.; Bamane S. R. Nanostructured Spinel $\mathrm{ZnFe}_{2} \mathrm{O}_{4}$ for the Detection of Chlorine Gas.

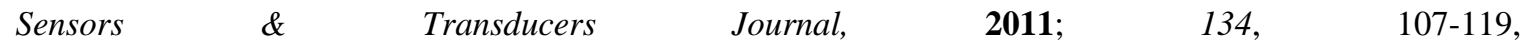
https://www.researchgate.net/publication/230751151_Nanostructured_Spinel_ZnFe2O4_for_the_Detection of_Chlorine_Gas.

34. Shelke, R. N.; Pansare, D. N.; Sarkate, A. P.; Karnik, K. S.; Sarkate, A. P.; Shinde, D. B.; Thopate, S. R. Synthesis of (Z)-5-(substituted benzylidene)-2-((substituted phenyl) amino)thiazol-4(5H)-one analogues with antitubercular activity. J. Taibah Uni Sci. 2019, 13, 678-686, https://doi.org/10.1080/16583655.2019.1622846.

35. Shelke, R. N.; Pansare, D. N.; Pawar, R. P.; Shinde, D. B.; Thopate, S. R. Synthesis of 2-((5-benzylidene-4oxo-4,5-dihydrothiazol-2-yl)-substituted amino acids as anticancer and antimicrobial agents. Eur. Chem. Bull. 2019, 8, 63-70, https://doi.org/10.17628/ecb.2019.8.63-70.

36. Pansare, D. N.; Shelke, R. N.; Khade, M. C.; Jadhav, V. N.; Pawar, C. D.; Jadhav, R. A.; Bembalkar, S. R. New thiazolone derivatives: design, synthesis, anticancer and antimicrobial activity. Eur. Chem. Bull. 2019, 8, 7-14, https://doi.org/10.17628/ecb.2019.8.7-14.

37. Pansare, D. N.; Shelke, R. N.; Shinde, D. B. A facial synthesis and anticancer activity of (Z)-2-((5-(4nitrobenzylidene) -4-oxo-4,5-dihydrothiazol-2-yl)amino) substituted acid. J. Het. Chem. 2017, 54, 30773086, https://doi.org/10.1002/jhet.2919.

38. Sarkate, A. P.; Pansare, D. N.; Karnik, K. S.; Kale, I. A.; Bahekar, S. S.; Shinde, D. B. Microwave assisted copper-catalyzed synthesis of substituted benzamides through decarboxylative C-N cross coupling. Curr. Micro. Chem. 2017, 4, 163-167, https://doi.org/10.2174/2213335603666161017120230

39. Shelke, R. N.; Pansare, D. N.; Pawar, C. D.; Shinde, D. B.; Thore, S. N.; Pawar, R. P.; Bembalkar, S. R. Synthesis of Novel 2H-Pyrano [2,3-D]Thiazole-6-Carbonitrile Derivatives in Aqueous Medium. Res. Rev. J. Chem. 2016, 5, 29-36, http://www.rroij.com/open-access/synthesis-of-novel2hpyrano23dthiazole6carbonitrile-derivatives-in-aqueous-medium-.php?aid=76025.

40. Pawar, C. D.; Pansare, D. N.; Shinde, D. B. Synthesis and antiproliferative evaluation of new (4-substituted3,4-dihydro-2H-benzo[b][1,4]oxazin-2-yl)methane substituted sulfonamide derivatives Eur. J. Chem. 2017, 8, 384-390, https://doi.org/10.5155/eurjchem.8.4.384-390.1635.

41. Pawar, C. D.; Pansare, D. N.; Shinde, D. B. Synthesis and antiproliferative activity of 3-(substituted)-4,5,6,7tetrahydro-6-(substituted)-1H-pyrazolo[3,4-c]pyridine. Derivatives. Eur. J. Chem. 2017, 8, 400-409, https://doi.org/10.5155/eurjchem.8.4.400-409.1645.

42. Pawar, C. D.; Pansare, D. N.; Shinde, D. B. Synthesis, anti-proliferative activity, SAR and Kinase inhibition studies of thiazol-2-yl- substituted sulfonamide derivatives. J. Chin. Chem. Soc. 2019, 66, 257-264, https://doi.org/10.1002/jccs.201800312.

43. Pansare, D. N.; Mulla N. A.; Pawar, C. D.; Shende, V. R.; Shinde, D. B. One pot three components microwave assisted and conventional synthesis of new 3-(4-chloro-2-hydroxyphenyl)-2-(substituted) thiazolidin-4-one as antimicrobial agents. Bioorg. Med. Chem. Lett. 2014, 24, 3569-3573, https://doi.org/10.1016/j.bmcl.2014.05.051. 
44. Pansare, D. N.; Shinde, D. B. A facile synthesis of (Z)-5-(substituted)-2-(methylthio)thiazol-4(5H)-one using microwave irradiation and conventional method. Tet. Lett. 2014, 55, 1107-1110, https://doi.org/10.1016/j.tetlet.2013.12.113.

45. Chavan, P.; Bangale, S.; Pansare, D.; Shelke, R.; Jadhav, S.; Tupare, S.; Kamble, D.; Rai, M. Synthesis of substituted pyrimidine using $\mathrm{ZnFe}_{2} \mathrm{O}_{4}$ nanocatalyst via one pot multi-component reaction ultrasonic irradiation. J. Het. Chem. 2020, 57, 3326-3333, https://doi.org/10.1002/jhet.4048.

46. Government of India, The Ayurvedic Pharmacopoeia of India, Part-I, Vol. II. New Delhi: Department of Indian Systems of Medicine \& Homeopathy. 2001, 155.

47. Gandhidasan, R.; Thamaraichelvan, A.; Baburaj, S. Anti-Inflammatory Action of Lannea coromandelica by HRBC Membrane Stabilization. Fitoterapia 1991, 62, https://www.scienceopen.com/document?vid=5a94a6a2-16fd-42e0-80dd-66d2aeb891d1.

48. Rang, H. P.; Dale, M. M.; Ritter, J. M.; Moore, P. K. Antinociceptive, Anti-Inflammatory and Antidepressant potential of methanolic extract of Celosia argentea Linn. Pharmacology. 5th ed. New Delhi India:Elsevier Science Ltd. 2011, 318-335, https://doi.org/10.22270/jddt.v9i2-s.2700. 